\section{TURISMO NO BRASIL DIANTE DA CONJUNTURA}

\author{
Maria Lucia Pires Nobre ${ }^{1}$
}

RESUMO: Analisa as dificuldades da atividade turística diante dos efeitos econômico-sociais da conjuntura brasileira. Destaca o turismo como uma das saídas para as várias crises em que se encontra o Brasil, inclusive a do seu próprio turismo. Enfoca o Mercosul como estratégia imediata para implementação do turismo sem fronteiras, promovendo mais integração entre paises vizinhos sul-americanos. Comenta a integração política e econômica e suas implicações sociais, altamente favoráveis a todos os países signatários do Tratado de Assunção - Mercosul.

PALAVRAS-CHAVE: Turismo brasileiro: dificuldades; estratégias; turismo sem fronteiras; Mercosul.

ABSTRACT: Analyses the difficulties of the tourist activity before the social and economic effects of the Brazilian conjuncture. Detach tourism as one of the exits for the various crisis Brazil is coming across, inclusive in tourism. Focus Mercosul as an instant strategy for the implementation of the tourism without borders, promoting integration between the neighbouring South-American countries. Comments on the political/economical integration and its favourable and highly social implications to all countries signatories of the Assunción Treaty - Mercosul.

KEY WORDS: Brazilian tourism; difficulties; strategies; tourism without borders; Mercosul.

1 Bacharel em Turismo pela Faculdade de Turismo, Universidade Estácio de Sá, Rio de janeiro. Curso de Especialização Turística, Centro Interamericano de Capacitação Turística - CICATUR, México. Técnica da Embratur - Instituto Brasileiro de Turismo, Rio de Janeiro.

End. para corresp.: Rua Figueiredo Magalhães, 47 - apto. 401 - Copacabana

- CEP 22031 - Rio de Janeiro - RJ - Brasil.

\section{INTRODUÇÃO}

O Brasil, ocupa uma área geográfica quase equivalente à metade de todo o território sul-americano. Nos seus $8.511 .965 \mathrm{~km}^{2}$ é caracterizado como uma país de marcantes proporções continentais de extensa faixa litorânea sobre o Atlântico Sul, que se destaca como ponto de atração geopolítica de sua história. Além do imenso litoral leste, o Brasil ainda possui bacias fluviais como a do Amazonas e a união das bacias do Paraná-Paraguai, entre outras, vertentes naturais que influenciam e impulsionam a economia do país. Junto a potencialidade natural, de grande valor paisagístico, soma o seu patrimônio sócio-cultural, formalizando um conjunto de notável riqueza, inclusive para o turismo. $\mathrm{O}$ fato turístico, em sua essência, constitui um acontecimento de considerável importância, tanto pelo papel que ele representa no crescimento da economia, como pelas possibilidades que pode oferecer para o desenvolvimento sociocultural.

A despeito de todas essas potencialidades, o Brasil vive hoje as conseqüências de uma grave crise política e econômica de sérios reflexos sociais. Nesse contexto, a atividade turística atravessa uma situação difícil, convivendo há algum tempo com incertezas que condicionam a sua evolução. Essa imagem vem repercutindo negativamente no número de turistas internacionais, fazendo com que diminua o fluxo de visitantes nos seus grandes centros.

\section{ANÁLISE DA SITUAÇÃo}

Uma visão panorâmica da conjuntura mundial contempla um cenário de profundas mudanças nas relações econômicas, gerando um encadeamento de complexidades, onde a interdependência entre os países exige que tudo passa a ser do interesse de todos. Nessa análise conjuntural, os países em desenvolvimento tomam-se mais vulneráveis e o papel do Brasil, inserido integralmente no contexto latinoamericano do Sul, se ressente dos impactos do "neo-liberalismo" internacional.

$\mathrm{Na}$ configuração atual das relações econômicas comerciais entre países, mesmo não ocupando um lugar efetivo no programa global, as estatísticas mostram que o turismo continua seguindo como uma atividade econômica em expansão que movimenta cerca de $450 \mathrm{mi}$ - 
lhões de viagens internacionais ao ano, sem incluir os deslocamentos internos. Ainda que esse crescimento esteja mais lento, em comparação ao "boom" dos anos 80, os grandes centros turísticos mundiais se superam conquistando novos mercados. Buscam na competitividade e na qualidade dos serviços aumentar a venda de seu produto. Adaptam-se às mudanças através de novas tecnologias, servindo-se, por exemplo, da Telemática na operacionalização do setor turístico, tornando-o mais competitivo pela rapidez com que informa a um maior número de clientes e mais eficiente, na coordenação dos múltiplos serviços que oferece para atendimento dos vários segmentos da demanda.

É evidente que, no caso brasileiro, fatores econômicos vêm afetando o turismo interno e gerando dificuldades à comercialização do produto fora do país. Distâncias longas, tarifas altas, preços instáveis tomam difícil o enfrentamento de outros mercados não inflacionados, altamente competitivos.

Naturalmente existem limitações, quase ausência de estatísticas disponíveis sobre os fluxos de visitantes, prejudicando, algumas vezes, a demonstração dos resultados contábeis da Conta Turismo no Brasil. Também constantemente o turismo é considerado como atividade "de elite", o que não é verdadeiro, porquanto movimenta milhões de pessoas/ano. Por essa visão errônea, deixa de receber, de parte dos governos, uma devida atenção em investimentos públicos de infra-estrutura necessária, para que possa operar melhor os seus serviços.

Ademais, no mundo todo, o turismo pertence a um setor pouco estável, que o torna altamente sensível aos efeitos dos fatores sociais e políticos ou de economias que não se estabilizam e impedem à população o Direito ao Lazer. Decorre ainda uma constante pressão que a mídia internacional exerce, utilizando, muito convenientemente, uma imagem agravada ante fatos negativos divulgados. Nesse conjunto de dificuldades e sob os efeitos competitivos dos grandes mercados, o Brasil vivencia também um descompasso tecnológico do setor turístico, que o faz perder espaço para as economias de escala de âmbito internacional.

Do ponto de vista formal, o crescimento dos fluxos turísticos é determinado por vantagens comparativas que lhe são oferecidas. Nesse contexto, o enfrentamento das conseqüências do quadro descrito poderá ser amenizado pelas qualidades intrínsecas do produto turístico brasileiro.

\section{PRODUTO TURÍSTICO BRASILEIRO}

Partindo dessa premissa sobre vantagens comparativas, os atrativos turísticos brasileiros possuem determinantes excelentes, advin dos da própria Natureza. Aliado aos fatores climáticos favoráveis, o país desfruta de uma posição privilegiada, garantida pela continuidade geográfica traçada em sentido meridional, cuja abrangência gera uma diversidade de atrativos divididos por três climas distintos: equatorial, tropical e temperado.

Sempre existirá o brilhoso sol, em alguma de suas regiōes, permitindo a venda do produto por todo o ano.

Desse questionamento, faz-se necessário que uma vontade imperiosa venha revertcr a situação do turismo no Brasil. A partir de decisões claras, intermediando ações promocionais em políticas de comercialização efetivas e contínuas, efetuando a venda do produto diretamente nos mercados emissores conhecidos e conquistando novos mercados à procura de aumentar os canais de distribuição. Caracterizado por "produto excêntrico", distante dos grandes centros, pode ser transformado, por força mercadológica, em "produto cêntrico", com uma razão consciente de que o turismo é uma forte alternativa para o desagravamento dos problemas conjunturais, resultantes da estagnação econômica. Por força das mutações do cenário internacional, seguindo uma visão logística, surge uma realidade afastando o isolamento do continente sul-americano, trazendo a integração de seus mercados e vislumbrando uma forma de liberalização econômica para seus integrantes.

\section{INSERÇÃO DO TURISMO NO MERCOSUL}

Com o surgimento da nova ordem econômica em blocos comerciais, integração passa a ter um caráter irresistível. A constituição do Mercado Comum entre países do Cone Sul - Brasil, Argentina, Uruguai e Paraguai - traz como conseqüência a mudança da geografia econômica mundial.

O crescente fortalecimento do fenômeno de internacionalização da economia implica um desafio novo. Por iniciativa da ALADI - 
Associação Latina Americana da Integração - formalizou-se a inclusão de uma Comissão Especial de Turismo no Tratado MERCOSUL Essa comissão vem trabalhando estratégias de marketing e coordenando ações operacionais, com vistas a tarifas, destinos e eventos, dentro de um sistema de reciprocidade entre os países membros. Assim, foi criado o Air Pass MERCOSUL, instrumento de comercialização de viagens aéreas, vendidas fora do contexto geográfico da América do Sul, permitindo vantagens especiais aos estrangeiros que visitam, no mínimo, dois dos quatro países integrantes do MERCOSUL, com limite de permanência entre dez e trinta dias.

Entre as tarefas recomendadas, a Comissão se ocupa de:

a) unificar as franquias entre os países integrantes;

b) eliminar o registro de veículos em trânsito turístico desses países fronteiriços;

c) simplificar e homogeneizar os formulários de entrada e saída de passageiros;

d) autorizar os residentes permanentes dos Estados-Partes a transitarem neste território com o documento nacional de identidade do país de residência, sem outro requisito.

Como previsão, ainda para 1993, prepara-se a implantação do Pólo Turístico Internacional Iguaçu, na Zona das Cataratas.

A harmonização de políticas macroeconômicas passa a ser o elemento condicionante do sucesso dos programas de integração. A rapidez com que se espera concretizar o MERCOSUL - mesmo considerando uma etapa intermediária para conformação de uma zona de livre comércio - constitui um desafio para os países envolvidos, na busca de mais especialização e eficiência produtiva.

Nas divergências dos prós e contras do Tratado do MERCOSUL, o que se verifica é que, mesmo que haja razões conflitantes, o perigo maior é ficar fora. No momento em que o mundo começa a dividir-se em grandes blocos, quem não se integrar para crescer e disputas espaço, não terá lugar no mundo das trocas comerciais onde o objetivo é aumentar os padrões de qualidade e competitividade internacionais, tendo como meta o aumento dos mercados.

\section{CONCLUSÃO}

No âmbito social, o papel do turismo foi precursor, partindo na frente, em várias oportunidades. Muito antes da formação dos "blocos regionais", o turismo já se estabelecia como instrumento de integração e desenvolvimento, colocando à disposição dos homens espaços desconhecidos para seu desfrute e seu direito de transitar livremente, fora de sua residência, sob os mais diversificados pretextos.

É freqüente o turismo ser tratado como "instrumento de paz". No seu âmbito social acontece o encontro entre pessoas que, apesar do idioma, raça, cultura, ideologia ou religião, encontram, a partir dalí, um ponto comum para o seu entendimento.

A configuração do MERCOSUL se dá em contexto econômico bastante difícil para os dois principais envolvidos - Brasil e Argentina -, pois ambos possuem estruturas complexas, exigindo reestruturações de base que envolvem reformas econômicas, políticas e institucionais, substituindo o quadro de crises e instabilidade por indutores de desenvolvimento.

É necessáriointegrar e competir. Integrar, eliminadoas desigualdades e ampliando o mercado. Competir, modernizando os sistemas de produção, distribuição e administração.

A implantação da via expressa - a "freeway" - ligando o Rio de Janeiro a Buenos Aires, representa uma concepção lógica de um projeto de integração. No seu eixo de influência, deve-se consolidar uma região, que certamente virá a ser o caminho do desenvolvimento efetivo do turismo, vitrine do MERCOSUL, quando de seu pleno funcionamento.

\section{BIBLIOGRAFIA}

NOBRE, Maria Lucia Nobre. 1992. O turismo como fato social fundamental na sociedade moderna. Rio de Janeiro: Escola Superior de Guerra, 100p. (ESGDepto. de Estudos-Curso de Altos Estudos de Política e Estratégia, TE-92, Tema 246)

SIMONSEN ASSOCIADOS. Mercosul - O desafio do marketing de integração. Makron Books. 